\title{
Determination of Molecular and "Truly" Free Sulfur Dioxide in Wine: A Comparison of Headspace and Conventional Methods
}

\author{
Todd W. Jenkins, ${ }^{1,3}$ Patricia A. Howe,,${ }^{1,2}$ Gavin L. Sacks, ${ }^{2}$ \\ and Andrew L. Waterhouse ${ }^{1 *}$
}

\begin{abstract}
Conventional methods such as Ripper titration and aeration-oxidation (A-O) are widely used for the analysis of sulfur dioxide $\left(\mathrm{SO}_{2}\right)$ in wine. However, the free $\mathrm{SO}_{2}$ reported by these procedures is overestimated due to dissociation of weakly bound $\mathrm{SO}_{2}$ forms during the analysis, particularly from anthocyanin-bisulfite complexes. "Truly" free $\mathrm{SO}_{2}$ in wine can be determined from the headspace $\mathrm{SO}_{2}$ concentration of an equilibrated wine sample. A headspace $\mathrm{SO}_{2}$ method based on gas detection tubes (HS-GDT) was recently described but is not readily automated. While solid phase microextraction (SPME) yielded poor precision in our experiments, our new method, based on static headspace gas chromatography and sulfur chemiluminescence detection (HS-GC-SCD), is readily automated and achieves high precision $(<5 \%)$ and low limits of detection $\left(0.033 \mathrm{mg} / \mathrm{L}\right.$ molecular $\mathrm{SO}_{2}$, or $\sim 1 \mathrm{mg} / \mathrm{L}$ free $\mathrm{SO}_{2}$ in wine at pH 3.5). A-O, Ripper, HS-GC-SCD, and HS-GDT methods were compared on a diverse set of wine samples. Results from HS-GC were correlated with those from the HS-GDT method $\left(\mathrm{r}^{2}=0.92\right)$ and achieved higher precision (relative standard deviation $=3.7 \%)$. HS-GC was highly correlated with A-O in white wines $\left(r^{2}=0.85\right.$, slope $\left.=0.90\right)$ but had weaker correlation for red wines $\left(r^{2}=0.71\right.$, slope $\left.=0.44\right)$. The flexibility of GC for other procedures as well as its stability and low operating costs per sample make it an attractive option, and headspace methods have been shown to be better for predicting microbial stability in red wines.
\end{abstract}

Key words: gas chromatography, headspace, sulfur chemiluminescence, sulfur dioxide, "truly" free $\mathrm{SO}_{2}$, wine analysis

Sulfur dioxide $\left(\mathrm{SO}_{2}\right)$ is the oldest and arguably one of the most important additives used in winemaking. When present in sufficient concentration, $\mathrm{SO}_{2}$ has five major effects in wine/ musts: (1) $\mathrm{SO}_{2}$ is a strong antimicrobial agent and provides a protection against a wide array of detrimental microorganisms; (2) it is an effective antioxidant that consumes oxidants such as hydrogen peroxide or quinones formed during the course of wine/must oxidation; (3) it can inhibit polyphenol oxidase enzymes present in grapes; (4) it reversibly binds and bleaches wine pigments, particularly monomeric antho-

\footnotetext{
${ }^{1}$ Department of Viticulture and Enology, University of California, Davis, CA 95616; ${ }^{2}$ Department of Food Science, Cornell University, Ithaca, NY 14853; and ${ }^{3}$ current address: The Wine Group, LLC, 4596 Tesla Road, Livermore, CA 94550 .

*Corresponding author (alwaterhouse@ucdavis.edu; tel: +1-530-752-4777)

Acknowledgments: The authors gratefully thank Constellation Brands, St. Helena, CA, for their collaboration and generous donation of wine samples. Additional wine samples were donated from The Wine Group, Livermore, CA. Funding for this project was provided by the American Vineyard Foundation and from the Henry A. Jastro Shields Graduate Research Award. The authors declare no conflicts of interest.

Manuscript submitted July 2019, revised Dec 2019, accepted Feb 2020

Copyright (C) 2020 by the American Society for Enology and Viticulture. All rights reserved.

By downloading and/or receiving this article, you agree to the Disclaimer of Warranties and Liability. The full statement of the Disclaimers is available at http://www.ajevonline.org/content/proprietary-rights-notice-ajev-online. If you do not agree to the Disclaimers, do not download and/or accept this article. doi: 10.5344/ajev.2020.19052
}

cyanins; and (5) it reversibly binds aldehydes and ketones produced by oxidation or during fermentation, rendering them non-odorous (Waterhouse et al. 2016).

$\mathrm{SO}_{2}$ gives a weak, diprotic acid in aqueous solution $\left(\mathrm{pK}_{\mathrm{a} 1}=\right.$ $1.81, \mathrm{pK}_{\mathrm{a} 2}=7.20$ in $\mathrm{H}_{2} \mathrm{O}$ at $20^{\circ} \mathrm{C}$ ) and can exist in molecular $\left(\mathrm{SO}_{2}\right)$, bisulfite $\left(\mathrm{HSO}_{3}{ }^{-}\right)$, or sulfite $\left(\mathrm{SO}_{3}{ }^{2-}\right)$ forms. In the typical $\mathrm{pH}$ range of wine (3.0 to 4.0), the dominant species is the bisulfite anion, which acts as an antioxidant and participates in various binding/complexing reactions. Molecular $\mathrm{SO}_{2}$, the main antimicrobial form of $\mathrm{SO}_{2}$, is present at only a small fraction $(<5 \%)$ of the $\mathrm{HSO}_{3}{ }^{-}$concentration at wine $\mathrm{pH}$. $\mathrm{SO}_{3}{ }^{2-}$ is present at even a smaller fraction of the $\mathrm{HSO}_{3}{ }^{-}$concentration $(<0.1 \%)$ at wine $\mathrm{pH}$; thus, its influence on wine stability is likely negligible. $\mathrm{SO}_{2}$ in wine is further divided into two classes: free and bound. Free $\mathrm{SO}_{2}$ is defined as the sum of molecular and bisulfite forms and is the class with antimicrobial, antioxidant, and enzyme-inhibiting properties. Bound $\mathrm{SO}_{2}$ comprises the bisulfites that react (both weakly and strongly) with other molecules within the wine matrix and do not exhibit those protective properties, with some exceptions (Wells and Osborne 2011). The sum of the free and bound sulfites defines the "total" sulfite concentration (Buechsenstein and Ough 1978).

To obtain enologically useful information, analytical methods for $\mathrm{SO}_{2}$ must distinguish between the free form with its protective properties and the bound forms, which do not have these properties. Common analytical methods for free $\mathrm{SO}_{2}$ in wineries include iodometric titration (Ripper method) and aeration-oxidation (A-O) method (Iland et al. 1993, UrbanoCuadrado et al. 2004). These standard methods utilize an 
initial acidification step to avoid interferences from phenolics (Ripper) or to favor the molecular $\mathrm{SO}_{2}$ species prior to a separation step (A-O and related flow injection or segmented flow analysis methods). This acidification step, coupled with consumption of free $\mathrm{SO}_{2}$ during the course of analysis, can result in release and subsequent measurement of weakly bound $\mathrm{SO}_{2}$, particularly from anthocyanin-bisulfite complexes. As a result, standard measurement approaches will overestimate free $\mathrm{SO}_{2}$, particularly in red wines (Coelho et al. 2015).

This artefactual overestimation of free $\mathrm{SO}_{2}$ can be avoided by measuring the headspace $\mathrm{SO}_{2}$ concentration of an equilibrated wine sample. This concentration of headspace $\mathrm{SO}_{2}$ can be related to the aqueous molecular $\mathrm{SO}_{2}$ concentration by its Henry's Law coefficient $(H)$, which can then be related to the concentration of "truly" free $\mathrm{SO}_{2}$ by $\mathrm{pK}_{\mathrm{a} 1}$ and the Henderson-Hasselbalch equation. To calculate free $\mathrm{SO}_{2}$, the ethanol concentration, $\mathrm{pH}$, and temperature of the wine sample must be accurately known to establish the correct values of $\mathrm{pK}_{\mathrm{a} 1}$ and $H$. A recently described approach used a syringe to create an equilibrated enclosed headspace above a wine sample and then expel the headspace through a commercial gas detection tube (GDT). The GDTs contain a colorimetric $\mathrm{SO}_{2}$-selective reagent such that length of discoloration on the GDT is proportional to the analyte concentration. The HSGDT technique does not involve $\mathrm{pH}$ shifts, sample dilution, or temperature changes, and thus avoids disturbances in $\mathrm{SO}_{2}$ equilibria in wine or contributions from weakly bound $\mathrm{SO}_{2}$ (Coelho et al. 2015). The authors observed that A-O resulted in an approximately three-fold overestimation of free $\mathrm{SO}_{2}$ in red wines compared to HS-GDT. The HS-GDT approach was later shown to yield more accurate predictions of yeast survivability and viability during challenge tests, suggesting that "truly" free $\mathrm{SO}_{2}$ measurements may be of greater relevance for prediction of antimicrobial activity (Howe et al. 2018).

Although easy to implement, one drawback of the HS-GDT approach is that it is not readily automated. Other potentially more automatable approaches for indirect and direct measurement of "truly" free $\mathrm{SO}_{2}$ have been described, including capillary electrophoresis (CE) and headspace gas chromatography (HS-GC) coupled to an electrolytic conductivity detector (ECD). These studies have come to similar conclusions that free $\mathrm{SO}_{2}$ may be overestimated by up to an order of magnitude in red wines, although none of the methods appear to be widely used (Davis et al. 1983, Boulton et al. 1996, Collins and Boulton 1996).

The coupling of HS-GC with a sulfur chemiluminescence detector (SCD) for analysis of $\mathrm{SO}_{2}$ and other volatile sulfur compounds in unadjusted wine samples was recently described (Ontanon et al. 2019). HS-GC-SCD is readily automated and has excellent selectivity for sulfur compounds. Because samples were not adjusted or heated prior to or during analysis, the $\mathrm{SO}_{2}$ measured by HS-GC-SCD should be proportional to the "truly" free $\mathrm{SO}_{2}$. However, this earlier report did not compare results for wines analyzed by HS-GC-SCD to those analyzed by other analytical approaches for measuring $\mathrm{SO}_{2}$. In this work, we reported development of an HS-GC-SCD method for "truly" free $\mathrm{SO}_{2}$, and compared it to other methods for measuring $\mathrm{SO}_{2}$ (HS-GDT, A-O, Ripper). We also compared the differences between headspace methods and conventional methods (A-O, Ripper) for measurement of substances that might form metastable bound $\mathrm{SO}_{2}$ that could be released during conventional analyses to evaluate a basis for the discrepancy between the headspace and conventional methods.

\section{Materials and Methods}

Chemicals. Potassium metabisulfite (97\%); acetaldehyde (99\%); 2-ketoglutaric acid (99\%); pyruvic acid (99\%); 2,4-dinitrophenylhydrazine (DNPH); ammonium dihydrogen phosphate ( $\geq 95 \%)$; formic acid ( $\geq 95 \%)$; methanol $(\geq 99.9 \%)$; and acetonitrile $(\geq 99.9 \%)$ were obtained from Sigma-Aldrich. L-Tartaric acid (99\%) was obtained from Fisher Scientific. Ethanol (anhydrous, $\geq 99.5 \%$ ) was obtained from Decon Laboratories. Hydrogen peroxide $(30 \% \mathrm{w} / \mathrm{v})$, sodium hydroxide $(10 \%, 0.1 \mathrm{~N}$, and $0.01 \mathrm{~N}), o$-phosphoric acid $(85 \%)$, sulfuric acid $(25 \%)$, starch $(1 \%)$, and iodine $(0.02 \mathrm{~N})$ were obtained from Enartis Vinquiry. Ethyl methyl sulfide $(1000 \mu \mathrm{g} / \mathrm{mL})$ was obtained from SPEX CertiPrep.

$\mathrm{SO}_{2}$ working standards. $\mathrm{SO}_{2}$ stock solutions at nominal concentrations of $6000 \mathrm{mg} / \mathrm{L}$ as $\mathrm{SO}_{2}$ were prepared weekly by dissolving potassium metabisulfite in a $10 \%(\mathrm{v} / \mathrm{v}$ in water) solution of methanol to avoid $\mathrm{SO}_{2}$ autooxidation. Working standards were then prepared as needed by adding an appropriate volume of a stock $\mathrm{SO}_{2}$ solution to model wine. Model wine solution was prepared in ultrapure water containing $4 \mathrm{~g} / \mathrm{L}$ of tartaric acid and $10 \%$ ethanol and adjusted with $\mathrm{NaOH}$ solution to a $\mathrm{pH}$ of 3.50 . The ethanol concentration was verified using an Alcolyzer Wine $\mathrm{M}$. The true $\mathrm{pKa}\left(\mathrm{pK}_{\mathrm{M}}\right)$ for $\mathrm{SO}_{2}$ in each batch of model wine was determined using the following calculations, and the concentration of each of the calibration standards was calculated using the HendersonHasselbalch equation.

Estimation of $\mathrm{pK}_{\mathrm{a} 1}\left(\mathrm{pK}_{\mathrm{M}}\right)$ of $\mathrm{SO}_{2}$ and calculation of free $\mathrm{SO}_{2}$ from molecular $\mathrm{SO}_{2}$. The following equations were built from a multiple linear regression model using XLSTAT (Addinsoft) to predict the $\mathrm{pK}_{\mathrm{a}}$ values contained in published tables (Usseglio-Tomasset and Bosia 1984).

To estimate the value of the thermodynamic constant $\mathrm{pK}_{\mathrm{T}}$ for various alcohol concentrations (Alc., \%v/v) and temperatures $\left(\mathrm{T},{ }^{\circ} \mathrm{C}\right)$, the following equation was used (Equation 1).

$$
\begin{aligned}
& \text { Estimation of } p K_{T} \text {. } \\
& p K_{T}=0.655664+(0.0698386 * T)+(0.02015 * \text { Alc. }) \\
& -\left(0.000621693 * T^{2}\right)
\end{aligned}
$$

To estimate the value of the coefficients A and B for various alcohol concentrations and temperatures, the following two equations were used (Equations 2 and 3).

Estimation of A constant.

$A=0.482724+(0.000883782 * T)+(0.00443752 *$ Alc. $)$ $+\left(0.00000595973 * T^{2}\right)+\left(0.0000489638 *\right.$ Alc. $\left.^{2}\right) \quad$ Eq. 2

Estimation of $B$ constant.

$B=1.61645+(0.000935347 * T)+(0.00479931 *$ Alc.$)$

$+\left(0.00000492357 * T^{2}\right)+\left(0.0000315093 *\right.$ Alc. $\left.^{2}\right) \quad$ Eq. 3 
Finally, the value of the mixed dissociation constant, $\mathrm{pK}_{\mathrm{M}}$, as a function of $\mathrm{pK}_{\mathrm{T}}$, the coefficients $\mathrm{A}$ and $\mathrm{B}$, and the ionic strength (I) was determined by Equation 4 below.

Estimation of $p K_{M}$.

$$
p K_{M}=p K_{T}-\frac{(A \sqrt{I})}{(1+B \sqrt{I})}
$$

Because the measurement of ionic strength (I) is complex and labor intensive, a typical ionic strength of $0.056 \mathrm{M}$ can be assumed (the typical range for ionic strength in wine is $0.016 \mathrm{M}$ to $0.100 \mathrm{M}$ ) and was used in the calculation of $\mathrm{pK}_{\mathrm{M}}$ (Berg and Keefer 1958, 1959, Ough et al. 1982, Abgueguen and Boulton 1993) without resulting in significant error in estimation of free $\mathrm{SO}_{2}$ (Coelho et al. 2015).

The value of $\mathrm{pK}_{\mathrm{M}}$ can then be used in the Henderson-Hasselbalch equation (Equation 5) to determine the molecular and free species of $\mathrm{SO}_{2}$ as a function of $\mathrm{pH}$.

Modified Henderson-Hasselbalch equation.

$$
\left[\text { Molecular } \mathrm{SO}_{2}\right]=\frac{\left[\text { Free } \mathrm{SO}_{2}\right]}{1+10^{\left(\mathrm{pH}-p K_{M}\right)}}
$$

$\mathrm{SO}_{2}$ measurements using previously described approaches: A-O, Ripper, and HS-GDT. $\mathrm{SO}_{2}$ analysis by A-O (Iland et al. 1993), Ripper (Vahl and Converse 1980), and HS-GDT (Coelho et al. 2015) were all performed in triplicate for each wine. The Ripper method was also used to measure total $\mathrm{SO}_{2}$.

$\mathbf{S O}_{2}$ measurement by HS-GC-SCD. Analysis of molecular and free $\mathrm{SO}_{2}$ were performed with an Agilent 7890B gas chromatograph coupled with an Agilent 8355 SCD (Agilent Technologies). The capillary column used was an Agilent DBWAX-UI $(30 \mathrm{~m} \times 0.25 \mathrm{~mm}$ i.d. $\times 0.25 \mu \mathrm{m}$ film thickness $)$. The autosampler was a PAL3 RSI from CTC analytics operated in static headspace mode. The $2.5-\mathrm{mL}$ gas-tight syringe was heated to $40^{\circ} \mathrm{C}$ to prevent condensation of the headspace sample in the syringe. Injections were split (4:1 ratio) at an injector temperature of $200^{\circ} \mathrm{C}$. Before and after injection, the syringe was purged with pure He for $90 \mathrm{sec}$. The temperature program for the final method started at $50^{\circ} \mathrm{C}$, which was maintained for $2.5 \mathrm{~min}$, increased at a rate of $50^{\circ} \mathrm{C} / \mathrm{min}$ to $220^{\circ} \mathrm{C}$, and held at this temperature for $2 \mathrm{~min}$. The complete chromatogram took $7.9 \mathrm{~min}$, with a total GC cycle time of $10.5 \mathrm{~min}$ between injections. The carrier gas was He (44.2 $\mathrm{cm} / \mathrm{sec}$ ) in constant flow mode. The SCD burner temperature was $800^{\circ} \mathrm{C}$ with a hydrogen flow rate of $100 \mathrm{~mL} / \mathrm{min}$ and an air flow rate of $40 \mathrm{~mL} / \mathrm{min}$. The SCD pressure was 6 Torr with the controller at 200 Torr.

Immediately after opening a bottle, $15 \mathrm{~mL}$ of room temperature wine $\left(23^{\circ} \mathrm{C}\right)$ was transferred into a $20-\mathrm{mL}$ amber crimp top headspace vial and spiked with $50 \mu \mathrm{L}$ of internal standard ( $30 \mu \mathrm{g} / \mathrm{mL}$ ethyl methyl sulfide in methanol) for each analysis. The vials were then capped with magnetic crimp seals with PTFE/silicone septa. If not already equilibrated to room temperature, the samples were equilibrated for $1 \mathrm{hr}$ before running the procedure. HS-GC-SCD analyses were then performed as described above. Because a headspace volume of $50 \mathrm{~mL}$ at room temperature has already been shown to take a minimum of $5 \mathrm{~min}$ to fully equilibrate, the equilibration time for the GC vials with $5 \mathrm{~mL}$ of headspace volume was assumed to be equivalent or less (Coelho et al. 2015). The analytical characteristics of the method are summarized in Table 1.

Monomeric anthocyanins by high performance liquid chromatography (HPLC). The separation of the monomeric anthocyanins was conducted with reverse-phase HPLC using an Agilent 1100 series (Agilent Technologies) modular HPLC system based on the method described elsewhere (Ritchey and Waterhouse 1999). The HPLC system included a system controller, G1379A degasser, G1311A quaternary pump, G1313A autosampler, G1316A column compartment, and a G1315A DAD/UV-vis detector. Data was processed using ChemStation version B.04. Separation of anthocyanins was performed with a LiChrospher 100 RP-18 column $(4 \times$ $250 \mathrm{~mm}, 5 \mu \mathrm{m}$ particle size; Agilent Technologies). A guard column of the same material was also installed, and column temperature was maintained at $40^{\circ} \mathrm{C}$.

Briefly, the procedure used two mobile phase solutions for analysis. The solvents were (A) $50 \mathrm{mM}$ ammonium dihydrogen phosphate (Sigma-Aldrich $\geq 95 \%$ ) adjusted to $\mathrm{pH} 2.6$, and (B) 20\% Mobile A $+80 \%$ acetonitrile (v/v) (Sigma-Aldrich $\geq 99.9 \%$ ). The gradient used was: zero-time conditions were $94 \% \mathrm{~A}$ and $6 \% \mathrm{~B}$; the pumps were adjusted to $70 \% \mathrm{~A}$ and $30 \% \mathrm{~B}$ at $15 \mathrm{~min}$; to $50 \% \mathrm{~A}$ and $50 \% \mathrm{~B}$ at $30 \mathrm{~min}$; to $40 \%$ $\mathrm{A}$ and $60 \% \mathrm{~B}$ at $35 \mathrm{~min}$; and to $94 \% \mathrm{~A}$ and $6 \% \mathrm{~B}$ at $41 \mathrm{~min}$ (end of analysis). After a 10-min equilibrium period, the next sample was injected.

The concentration of total monomeric anthocyanins was determined by the summation of the peak areas measured at $520 \mathrm{~nm}$ for delphinidin 3-glucoside, pelargonidin, cyanidin 3-glucoside, pelargonidin 3-glucoside, delphinidin, malvidin 3-glucoside, and malvidin. The concentration was expressed as $\mathrm{mg} / \mathrm{L}$ of malvidin-3-glucoside equivalents.

Free and $\mathrm{SO}_{2}$-bound wine carbonyls by HPLC. Acetaldehyde, 2-ketoglutarate, and pyruvate were determined by HPLC after derivatization reaction with DNPH reagent (Sigma-Aldrich) as reported (Han et al. 2015). Briefly, aliquots of wine samples $(100 \mu \mathrm{L})$ were dispensed into a vial, followed by the addition of $20 \mu \mathrm{L}$ of freshly prepared $1120 \mathrm{mg} / \mathrm{L} \mathrm{SO}_{2}$ solution, $20 \mu \mathrm{L}$ of $25 \%$ sulfuric acid, and $140 \mu \mathrm{L}$ of $2 \mathrm{~g} / \mathrm{L}$ $\mathrm{DNPH}$ reagent. After mixing, the solution was allowed to react for $15 \mathrm{~min}$ at $65^{\circ} \mathrm{C}$ and then was promptly cooled to room temperature in a water bath. Carbonyl hydrazones were analyzed by HPLC using the system described above. In the chromatographic system, a ZORBAX Rapid Resolution HT,

Table 1 Method figures of merit.

\begin{tabular}{lc}
\hline Parameters & Analytical parameter \\
\hline Correlation coefficient & 0.997 \\
Linear range (molecular $\mathrm{SO}_{2} \mathrm{mg} / \mathrm{L}$ ) & $0.067-2.00$ \\
Limit of detection (molecular $\mathrm{SO}_{2} \mathrm{mg} / \mathrm{L}$ ) & 0.033 \\
Limit of quantification (molecular $\mathrm{SO}_{2} \mathrm{mg} / \mathrm{L}$ ) & 0.067 \\
$\mathrm{RSD}, \%^{\mathrm{a}}$ & 3.72 \\
\hline
\end{tabular}

a Based on triplicate analysis of 27 different wines. RSD, relative standard deviation. 
SB-C18 column $\left(1.8 \mu \mathrm{m}, 4.6 \times 100 \mathrm{~mm}^{2}\right.$; Agilent Technologies $)$ was used for separation. Separation was obtained using a flow rate of $0.75 \mathrm{~mL} / \mathrm{min}$ and column temperature of $35^{\circ} \mathrm{C}$, and the mobile phase solvents were (A) $0.5 \%$ formic acid (Sigma Aldrich $\geq 95 \%$ ) in water milli-Q and (B) acetonitrile (Sigma Aldrich $\geq 99.9 \%$ ). The gradient elution protocol was as follows: $35 \%$ B to $60 \%$ B (0 to $8 \mathrm{~min}$ ); $60 \%$ B to $90 \%$ B (9 to $13 \mathrm{~min}$ ); $90 \%$ B to $95 \%$ B (14 to $15 \mathrm{~min}, 2$-min hold); and $95 \%$ $\mathrm{B}$ to $35 \% \mathrm{~B}$ (16 to $20 \mathrm{~min}$, 4-min hold), with a total run time of $20 \mathrm{~min}$. Eluted peaks were measured at $365 \mathrm{~nm}$ and were compared with derivatized acetaldehyde, 2-ketoglutarate, and pyruvate standards (Sigma-Aldrich).

Analysis of alcohol, pH, and temperature. Alcohol. The ethanol content of all wine samples and model wines was determined using an Alcolyzer Wine M (Anton-Paar).

$p H$. The $\mathrm{pH}$ of all wine samples and model wines was measured using an Orion 5 Star (Thermo Scientific). The $\mathrm{pH}$ probe was calibrated daily using buffers of $2.00,4.01$, and $7.00 \mathrm{pH}$ standards. Slopes of each calibration ranged from 96 to $100 \%$.

Temperature. Sample temperature was measured using VWR Traceable Lollipop Water-Resistant Thermometers.

Wine samples. Table 2 shows the identity of the wines used to compare the four methods. Various wines $(n=27)$ covering a range of varieties, vintages, and appellations were donated from Constellation Brands.

Table 2 Wines used for the comparison of methods and respective sample codes.

\begin{tabular}{llc}
\hline Sample ID & \multicolumn{1}{c}{ Wine } & Wine type \\
\hline BLAU & 2015 Paso Robles Blaufränkisch & Red \\
CAB & 2015 California Cabernet Sauvignon & Red \\
MER 1 & 2014 Napa Valley Merlot & Red \\
MER 2 & 2015 Central Coast Merlot & Red \\
MER 3 & 2013 Paso Robles Merlot & Red \\
PIN 1 & 2016 Monterey County Pinot noir A & Red \\
PIN 2 & 2016 Monterey County Pinot noir B & Red \\
PIN 3 & 2015 Central Coast Pinot noir & Red \\
PORT & 2012 Napa Valley Port & Red \\
RED & 2015 California Red Blend & Red \\
ZIN 1 & 2014 Sonoma County Zinfandel & Red \\
ZIN 2 & 2013 Alexander Valley Zinfandel & Red \\
ZIN 3 & 2013 California Zinfandel & Red \\
ROSE & 2016 Central Coast Rose & Rose \\
BRUT & NV Brut Sparklinga & White \\
CHA 1 & 2014 Napa Valley Chardonnay & White \\
CHA 1 & 2015 Napa Valley Chardonnay & White \\
CHA 2 & 2015 California Chardonnay & White \\
CHA 3 & 2014 Central Coast Chardonnay & White \\
MOSC 1 & 2014 California Moscato & White \\
MOSC 2 & 2015 Napa Valley Moscato & White \\
MOSC 3 & 2016 Sonoma County Moscato & White \\
SAB 1 & 2015 Alexander Valley Fume blanc & White \\
SAB 2 & 2015 California Sauvignon blanc & White \\
VIO 1 & 2014 Central Coast Viognier & White \\
VIO 2 & 2015 Central Coast Viognier & White \\
WHITE & 2014 Central Coast White Blend & White \\
\hline NV N & &
\end{tabular}

${ }^{a} N V$ : Non-vintage.

\section{Results and Discussion}

In our initial work, we evaluated the use of solid-phase microextraction (SPME) followed by separation on a porous layer open tubular (PLOT) GC column, since similar methods have been used for analysis of other volatile sulfur compounds in wine. This initial approach used short SPME exposure times to avoid perturbation of equilibria but was determined to be unacceptable due to poor precision and excessive peak broadening on the PLOT column that was difficult to analyze (data not shown). We then evaluated static headspace injection with different columns (DB-Sulfur, DBWAX-ETR, and DB-WAX-UI). We selected the DB-WAX-UI column because it could achieve rapid separation of $\mathrm{SO}_{2}$ with gaussian peak shape, excellent peak precision $(2.8 \%$ relative standard deviation [RSD]), and a low limit of detection. The final GC parameters used were similar to a reported method, with the exceptions of eliminating the $\mathrm{SO}_{2}$ preconcentration step in favor of drawing a $0.500-\mathrm{mL}$ sample directly from the headspace vial with the autosampler and using ethyl methyl sulfide (EMS) as the internal standard (Carrascon et al. 2017). By design, the use of an SCD as opposed to a mass spectrometer detector was intended to improve sensitivity and selectivity to $\mathrm{SO}_{2}$. The selected column does degrade with time from the $\mathrm{SO}_{2}$ exposure and should be replaced after $\sim 200$ injections.

With the DB-WAX-UI column and corresponding GC parameters for this method, the elution time for the $\mathrm{SO}_{2}$ peak and EMS internal standard was $\sim 3.2$ and $1.8 \mathrm{~min}$, respectively, and neither of these co-eluted with any other potentially interfering compounds typically found in wine. A representative chromatogram of a 2014 Central Coast Viognier is shown in Figure 1.

Table 3 presents free $\mathrm{SO}_{2}(\mathrm{mg} / \mathrm{L})$ on a set of California wines as measured by the A-O, Ripper, HS-GDT, and HS-GC methods. The results of the A-O and Ripper methods will be referred to as "apparent" free $\mathrm{SO}_{2}$, and the free $\mathrm{SO}_{2}$ measured using the HS-GDT and HS-GC techniques will be referred to as "truly" free $\mathrm{SO}_{2}$. All analyses on each wine using each method were performed in triplicate to assess and compare the precision of the methods.

Table 4 tabulates other basic chemistry parameters of the wine samples analyzed in this set. The estimates of true $\mathrm{pKa}$

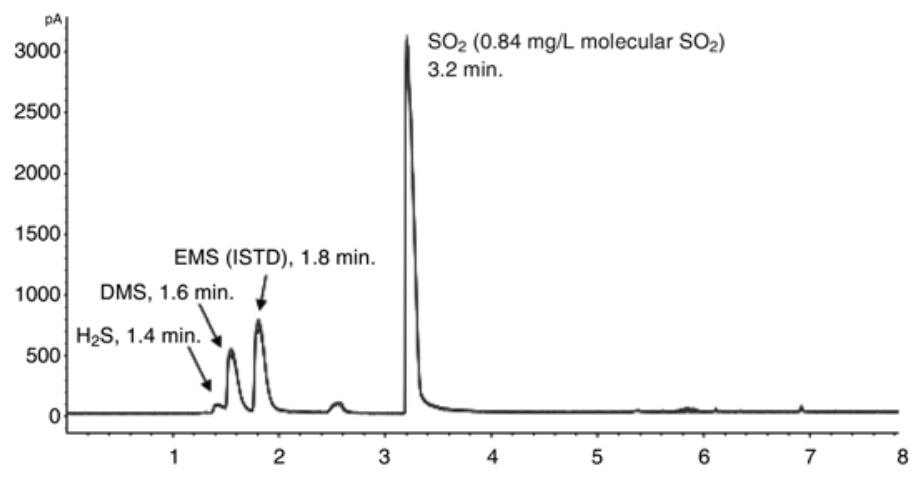

Figure 1 Chromatogram of a 2014 Central Coast Viognier. Column: DB-WAX-UI. Sampling method: Static headspace. DMS, dimethyl sulfide; EMS, ethyl methyl sulfide; ISTD, internal standard (EMS). 
based on alcoholic strength, temperature, and ionic strength are also shown. For $\mathrm{SO}_{2}$ measured by HS-GC, the formula for estimating the truly free $\mathrm{SO}_{2}$ is based on the UsseglioTommaset calculations (Usseglio-Tomasset and Bosia 1984). For $\mathrm{SO}_{2}$ measured by HS-GDT, a related approach was used in Coelho et al. (2015) for estimating the true pKa.

Because the temperatures of the HS-GC and HS-GDT analyses were not controlled beyond the prevailing ambient room temperature ( 18 to $21^{\circ} \mathrm{C}$ ), a few comparative analyses were conducted at non-equivalent temperatures. Specifically, analysis of the 2015 Paso Robles Blaufränkisch (BLAU), 2015 California Cabernet Sauvignon (CAB), and 2014 Napa Valley Chardonnay (CHA 1) by HS-GC and HS-GDT was at a $2{ }^{\circ} \mathrm{C}$ differential, with the $\mathrm{HS}-\mathrm{GC}$ analysis performed at $20^{\circ} \mathrm{C}$ and the HS-GDT analysis performed at $18^{\circ} \mathrm{C}$. Analysis of the 2014 Central Coast White Blend (WHITE), 2015 Central Coast Viognier (VIO 2), and 2014 Central Coast Chardonnay (CHA 3) samples also occurred at a $2{ }^{\circ} \mathrm{C}$ differential, with the HS-GC analysis performed at $25^{\circ} \mathrm{C}$ and the HS-GDT analysis performed at $23^{\circ} \mathrm{C}$. While the respective formulas for calculating the true $\mathrm{pKa}$ have built-in functions that account for the difference in temperature, it is unclear whether these are sufficient to overcome instances when analysis is done at a non-standard temperature or can account for slight variations in analysis temperature beyond $\pm 1^{\circ} \mathrm{C}$. Given the uncertainty, these data points were excluded from the statistical analysis.

The full comparison of analytical methods indicated that analytical precision of the A-O and Ripper methods were comparable and satisfactory, as both methods had RSDs (\%RSD) below 5\%. Both the A-O and Ripper methods had similar average standard deviations across the 27 wines analyzed ( 0.8 and $0.7 \mathrm{mg} / \mathrm{L}$ free $\mathrm{SO}_{2}$, respectively). A graphical comparison of the free $\mathrm{SO}_{2}$ results of the 27 wines by A-O and Ripper analysis is shown in Figure 2. The methods showed good agreement based on a regression analysis (slope $=1.02$, intercept $=2.8, \mathrm{r}^{2}=0.92$, Figure 2). The highest standard deviation in free $\mathrm{SO}_{2}$ measurement by A-O was observed in the analysis of the non-vintage Brut sparkling wine, which was likely due to dissolved $\mathrm{CO}_{2}$ that carried over into the peroxide trap used in the A-O procedure and resulted in an overtitration and subsequent over-reporting of apparent free $\mathrm{SO}_{2}$. Interestingly, the overall RSD for the Ripper method (3.79\%)

Table 3 Results of free $\mathrm{SO}_{2}$ in the test wines using aeration-oxidation (A-O), Ripper, headspace gas chromatography (HS-GC), and headspace gas detection tube (HS-GDT) methods. ${ }^{a}$

\begin{tabular}{|c|c|c|c|c|c|}
\hline \multirow[b]{2}{*}{ Sample ID } & \multirow[b]{2}{*}{ Wine type } & \multicolumn{2}{|c|}{ "Apparent" free $\mathrm{SO}_{2}(\mathrm{mg} / \mathrm{L})$} & \multicolumn{2}{|c|}{ "Truly" free $\mathrm{SO}_{2}(\mathrm{mg} / \mathrm{L})$} \\
\hline & & A-O & Ripper & HS-GC & HS-GDT \\
\hline RED & Red & $35.6(1.0)$ & $44.6(1.0)$ & $14.9(0.2)$ & $14.3(1.6)$ \\
\hline ZIN 1 & Red & $22.7(1.0)$ & $22.7(1.0)$ & $3.5(0.0)$ & $7.1(0.9)$ \\
\hline PIN 1 & Red & $30.6(1.0)$ & $36.7(0.7)$ & $14.9(0.8)$ & $15.1(0.0)$ \\
\hline BLAU & Red & $13.3(0.9)$ & $16.3(0.7)$ & $1.2(0.1)$ & $1.9(0.0)$ \\
\hline $\mathrm{CAB}$ & Red & $15.4(0.0)$ & $19.8(1.5)$ & $3.6(0.2)$ & $2.4(0.0)$ \\
\hline ZIN 2 & Red & $11.9(0.5)$ & $15.2(0.4)$ & $1.8(0.1)$ & $4.4(2.2)$ \\
\hline MER 1 & Red & $10.0(2.0)$ & $15.5(0.8)$ & $<\mathrm{LD}$ & $<\mathrm{LD}$ \\
\hline SAB 1 & White & $16.2(1.0)$ & $17.5(0.8)$ & $22.7(0.2)$ & $14.6(0.0)$ \\
\hline MER 2 & Red & $17.8(0.5)$ & $23.0(0.4)$ & $10.7(0.4)$ & $10.1(1.2)$ \\
\hline PIN 2 & Red & $22.8(0.5)$ & $30.4(0.4)$ & $16.3(1.5)$ & $11.3(2.4)$ \\
\hline MER 3 & Red & $11.7(0.5)$ & $15.9(0.6)$ & $5.3(0.6)$ & $<$ LD \\
\hline ROSE & Rose & $21.1(1.0)$ & $24.6(1.0)$ & $14.8(0.1)$ & $18.8(2.3)$ \\
\hline MOSC 1 & White & $8.8(0.0)$ & $9.5(0.0)$ & $2.5(0.0)$ & $3.4(0.0)$ \\
\hline PIN 3 & Red & $22.2(1.0)$ & $8.4(1.5)$ & $16.2(0.1)$ & $15.0(2.0)$ \\
\hline ZIN 3 & Red & $8.0(0.0)$ & $10.6(0.4)$ & $2.5(0.1)$ & $<\mathrm{LD}$ \\
\hline $\mathrm{CHA} 1$ & White & $20.9(0.0)$ & $25.7(0.4)$ & $15.5(0.5)$ & $18.2(2.5)$ \\
\hline $\mathrm{CHA} 2$ & White & $30.1(0.5)$ & $31.8(0.4)$ & $11.2(0.2)$ & $29.1(1.4)$ \\
\hline BRUT & White & $27.1(2.0)$ & $25.7(1.4)$ & $25.3(0.9)$ & $25.9(1.3)$ \\
\hline $\mathrm{CHA} 1$ & White & $17.2(1.6)$ & $18.1(0.0)$ & $16.0(0.6)$ & $15.3(2.2)$ \\
\hline WHITE & White & $14.3(1.6)$ & $14.3(0.7)$ & $13.7(0.5)$ & $13.6(0.9)$ \\
\hline MOSC 2 & White & $17.1(1.0)$ & $17.3(0.8)$ & $16.5(0.7)$ & $13.2(2.4)$ \\
\hline MOSC 3 & White & $7.4(1.0)$ & $10.5(0.8)$ & $6.8(0.5)$ & $7.3(1.5)$ \\
\hline VIO 1 & White & $19.5(0.9)$ & $23.1(0.9)$ & $19.4(0.2)$ & $21.8(2.7)$ \\
\hline PORT & Red & $<\mathrm{LD}$ & $6.4(0.8)$ & $<\mathrm{LD}$ & $<\mathrm{LD}$ \\
\hline SAB 2 & White & $23.3(0.9)$ & $24.8(0.4)$ & $23.5(1.2)$ & $23.1(7.1)$ \\
\hline VIO 2 & White & $15.2(1.0)$ & $17.3(0.8)$ & $15.8(0.4)$ & $11.5(1.2)$ \\
\hline $\mathrm{CHA} 3$ & White & $32.7(0.5)$ & $34.5(0.8)$ & $34.6(0.7)$ & $34.3(0.8)$ \\
\hline \multicolumn{2}{|c|}{ Average Std. Dev. (mg/L) } & 0.8 & 0.7 & 0.4 & 1.4 \\
\hline \multicolumn{2}{|c|}{ Average $\% \mathrm{RSD}^{\mathrm{b}}$} & $4.60 \%$ & $3.79 \%$ & $3.72 \%$ & $11.83 \%$ \\
\hline
\end{tabular}

aStandard deviation is shown in brackets. LD: limit of detection.

${ }^{\mathrm{b}} \mathrm{RSD}$ : Relative standard deviation. 
was lower than that for the A-O method (4.60\%). This finding is in contrast to findings from older studies that reported RSDs as high as 9.5 to $12 \%$ for the Ripper method (Buechsenstein and Ough 1978, Vahl and Converse 1980), but in agreement with more recent results from interlaboratory proficiency testing that observed little variation in precision between the two methods (Howe et al. 2015). The average absolute difference in free $\mathrm{SO}_{2}$ between the two methods was $3.3 \mathrm{mg} / \mathrm{L}$, with the maximum absolute difference $9.0 \mathrm{mg} / \mathrm{L}$. In most cases, the free $\mathrm{SO}_{2}$ results measured by Ripper were 0.7 to $5.8 \mathrm{mg} / \mathrm{L}$ higher than the free $\mathrm{SO}_{2}$ measured by A-O. This effect may be due to over-titration beyond the true end point by the operator to reach a visually detectable end point, especially in darkly pigmented samples, or due to the presence of interfering compounds such as reducing sugars or ascorbic acid (Iland et al. 1993).

With respect to the headspace techniques for measuring free $\mathrm{SO}_{2}$ (after mathematical conversion from molecular $\mathrm{SO}_{2}$ ), good linear agreement was observed between the HS$\mathrm{GC}$ and HS-GDT methods (slope $=0.90$, intercept $=1.1, \mathrm{r}^{2}=$ 0.92 , Figure 3). The average absolute difference in free $\mathrm{SO}_{2}$ between the two methods was $2.1 \mathrm{mg} / \mathrm{L}$ of free $\mathrm{SO}_{2}$, with a maximum absolute difference of $6.3 \mathrm{mg} / \mathrm{L}$. The HS-GC and HS-GDT methods had average standard deviations of 0.4 and $1.4 \mathrm{mg} / \mathrm{L}$ free $\mathrm{SO}_{2}$, respectively. In terms of analytical precision, the HS-GC technique had an RSD (3.72\%) that was appreciably lower than the RSD for the HS-GDT method (11.83\%). The lower precision of the HS-GDT method was likely due to the difficulty in reproducibly identifying the start and stop points of tube staining.

Since partitioning of $\mathrm{SO}_{2}$ in the headspace is governed by Henry's Law, effort was made to ensure that analysis of wines by the HS-GC and HS-GDT methods was performed at the same temperature $\pm 1^{\circ} \mathrm{C}$. The bottled wine samples were equilibrated at room temperature $\left(23^{\circ} \mathrm{C}\right)$ for a minimum of $24 \mathrm{hrs}$ prior to analysis. Temperature of the wine samples was recorded at the time of each batch of HS-GDT analysis. For the HS-GC analysis, the heating element of the sample agitator was turned off because precise temperature control was not available under $30^{\circ} \mathrm{C}$; therefore, samples in the $\mathrm{GC}$ vials were at the prevailing room temperature at the day and time of analysis. The laboratory is temperature controlled within 2 to $3^{\circ} \mathrm{C}$ for comfort but is not regulated to $\pm 1^{\circ} \mathrm{C}$. Despite those efforts, the difference in results between the HS-GC and HS-GDT methods could be due to slight differences $\left(>1^{\circ} \mathrm{C}\right)$ in

Table 4 Standard enological data and calculated $\mathrm{pK}_{\mathrm{a}}$ values on the tested wines.

\begin{tabular}{|c|c|c|c|c|c|c|}
\hline Sample ID & Wine type & $\begin{array}{l}\text { Alcohol } \\
\text { (\% v/v) }\end{array}$ & pH & $\begin{array}{c}\text { Total SO } \\
(\mathrm{mg} / \mathrm{L})\end{array}$ & $\begin{array}{c}\text { True pKa }\left(\mathrm{pK}_{\mathrm{M}}\right) \\
\text { (Usseglio- } \\
\text { Tomasett and } \\
\text { Bosia 1984) }\end{array}$ & $\begin{array}{c}\text { True pKa }\left(\mathrm{pK}_{\mathrm{M}}\right) \\
\text { (Coelho et al. } \\
\text { 2015) }\end{array}$ \\
\hline$\overline{R E D}$ & Red & 13.81 & 3.59 & 108.9 & 2.11 & 2.02 \\
\hline ZIN 1 & Red & 15.10 & 3.65 & 80.0 & 2.14 & 2.04 \\
\hline PIN 1 & Red & 13.81 & 3.68 & 76.9 & 2.11 & 2.02 \\
\hline BLAU & Red & 13.26 & 3.63 & 28.8 & $1.98^{a}$ & $2.01^{a}$ \\
\hline $\mathrm{CAB}$ & Red & 13.83 & 3.73 & 51.2 & $1.99^{a}$ & $2.02^{\mathrm{a}}$ \\
\hline ZIN 2 & Red & 15.26 & 3.78 & 43.3 & 2.14 & 2.04 \\
\hline MER 1 & Red & 15.38 & 3.63 & 87.6 & 2.14 & 2.04 \\
\hline SAB 1 & White & 13.86 & 3.32 & 78.3 & 2.12 & 2.02 \\
\hline MER 2 & Red & 13.66 & 3.49 & 76.9 & 2.11 & 2.02 \\
\hline PIN 2 & Red & 13.90 & 3.50 & 61.5 & 2.12 & 2.02 \\
\hline MER 3 & Red & 13.87 & 3.71 & 46.7 & 2.12 & 2.02 \\
\hline ROSE & Rose & 11.81 & 3.15 & 54.5 & 2.08 & 1.99 \\
\hline MOSC 1 & White & 8.44 & 3.57 & 103.3 & 2.01 & 1.95 \\
\hline PIN 3 & Red & 13.80 & 3.64 & 73.8 & 2.11 & 2.02 \\
\hline ZIN 3 & Red & 13.77 & 3.72 & 43.3 & 2.11 & 2.02 \\
\hline $\mathrm{CHA} 1$ & White & 14.16 & 3.53 & 76.7 & 2.12 & 2.02 \\
\hline $\mathrm{CHA} 2$ & White & 14.05 & 3.13 & 78.3 & 2.12 & 2.02 \\
\hline BRUT & White & 11.57 & 3.44 & 156.7 & 2.07 & 1.99 \\
\hline $\mathrm{CHA} 1$ & White & 13.86 & 3.37 & 83.2 & $1.99^{a}$ & $2.02^{\mathrm{a}}$ \\
\hline WHITE & White & 14.43 & 3.04 & 23.3 & $2.21^{b}$ & $2.03^{b}$ \\
\hline MOSC 2 & White & 8.00 & 3.35 & 113.3 & 2.00 & 1.94 \\
\hline MOSC 3 & White & 7.37 & 3.23 & 84.3 & 1.99 & 1.93 \\
\hline VIO 1 & White & 14.67 & 3.35 & 73.3 & 2.13 & 2.03 \\
\hline PORT & Red & 18.57 & 3.82 & 22.7 & 2.21 & 2.08 \\
\hline SAB 2 & White & 13.53 & 3.23 & 76.7 & 2.11 & 2.02 \\
\hline VIO 2 & White & 14.30 & 3.45 & 46.7 & $2.20^{\mathrm{b}}$ & $2.03^{b}$ \\
\hline $\mathrm{CHA} 3$ & White & 13.50 & 3.26 & 86.7 & $2.19^{b}$ & $2.01^{b}$ \\
\hline
\end{tabular}

aTemperature of analysis between headspace gas chromatography (HS-GC) and headspace gas detection tube (HS-GDT) differed by $2^{\circ} \mathrm{C}$ (HS-GC: $20^{\circ} \mathrm{C}$, HS-GDT: $18^{\circ} \mathrm{C}$ ).

bTemperature of analysis between HS-GC and HS-GDT differed by $2^{\circ} \mathrm{C}$ (HS-GC: $25^{\circ} \mathrm{C}, \mathrm{HS}-\mathrm{GDT}: 23^{\circ} \mathrm{C}$ ). All other samples were analyzed at $23^{\circ} \mathrm{C}$ by HS-GC and HS-GDT. 
analysis temperatures. Moreover, the imprecision of the end point determination with the GDTs may have amplified the apparent differences. Better temperature control should be possible to improve the correlation and precision. In practice, precise management of GDT temperatures would be difficult in a small-scale operation.

For red wines, measured free $\mathrm{SO}_{2}$ was higher with the A-O method than with the HS-GC method (range 5 to 20 $\mathrm{mg} / \mathrm{L}$, Table 3). On average, HS-GC free $\mathrm{SO}_{2}$ values for red wines were only $39 \%$ of those measured by A-O values $(61 \%$ lower). For white wines, better agreement in free $\mathrm{SO}_{2}$ values was observed between the HS-GC and A-O methods. On average, the free $\mathrm{SO}_{2}$ values for white wines measured by the $\mathrm{HS}-\mathrm{GC}$ method were $87 \%$ of the free $\mathrm{SO}_{2}$ values $(13 \%$ lower) determined by the A-O method for the same wines. Correlation between the HS-GC and A-O methods were also better for white wines $\left(r^{2}=0.85\right.$, Figure 4$)$ than for red wines $\left(r^{2}=0.71\right.$, Figure 4$)$. These results are comparable to previous work comparing HS-GDT and A-O, which reported that the values with HS-GDT were $51 \%$ and $13 \%$ lower for red and white wines, respectively (Coelho et al. 2015).

To determine the possible magnitude of the error contributed by the volatilization of $\mathrm{SO}_{2}$ into the $5 \mathrm{~mL}$ of headspace in the amber headspace vial, the following calculations were performed.

To estimate $\mathrm{K}_{\mathrm{H}}$ as a function of temperature (in ${ }^{\circ} \mathrm{C}$ ), the following equation (6) was used, which is the temperature correction for Henry's Law volatility constant $\mathrm{K}_{\mathrm{H}}$ :

$$
K_{H}=2.775 \times 10^{-5} \exp \left(\frac{3203}{T+273.16}\right)
$$

For example, for a liquid concentration $1.8 \times 10^{-5} \mathrm{M}$ molecular $\mathrm{SO}_{2}$ at $23^{\circ} \mathrm{C}$, the $\mathrm{K}_{\mathrm{H}}$ value is $1.38 \mathrm{M} / \mathrm{atm}$. Using Henry's Law, the vapor pressure of $\mathrm{SO}_{2}$ above the liquid would be $1.3 \times 10^{-5} \mathrm{~atm}$. The concentration of $\mathrm{SO}_{2}(\mathrm{in} \mathrm{g} / \mathrm{L}$ ) in the headspace is calculated using the following equation (7) and the known vapor pressure.

Calculation of headspace $\mathrm{SO}_{2}$ concentration at equilibrium.

$$
\mathrm{SO}_{2}(\mathrm{~g} / \mathrm{L})=\frac{\mathrm{VP}_{\mathrm{SO}_{2}}(\mathrm{~atm}) * 64.06 \mathrm{~g} / \mathrm{mol}}{22.4 \mathrm{~L} / \mathrm{atm}}
$$

Eq. 7

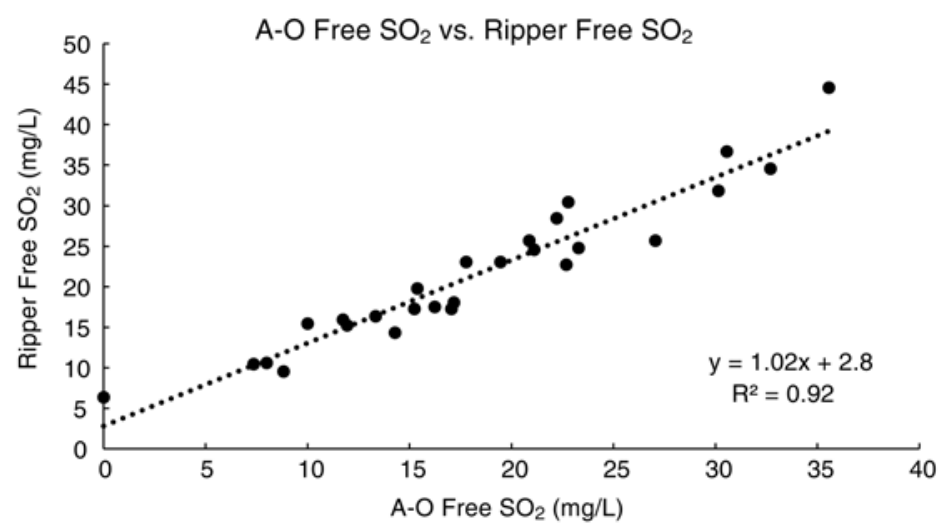

Figure 2 Correlation of free $\mathrm{SO}_{2}$ values measured by aeration-oxidation (A-O) and Ripper methods.
Further calculations showed that under these conditions, $\sim 1 \%$ of the $\mathrm{SO}_{2}$ in the sample was present in the $5 \mathrm{~mL}$ of headspace in the GC vial that contained $15 \mathrm{~mL}$ of sample, a small fraction that should not significantly disrupt the free $\mathrm{SO}_{2}$ equilibrium.

To evaluate the hypothesis that the discrepancies between the two analysis methods (HS-GC and A-O) could be explained by dissociation of metastable bisulfite complexes during analysis, the 27 wines used in the study were analyzed for the concentrations of major $\mathrm{SO}_{2}$ binders, including monomeric anthocyanins, acetaldehyde, pyruvate, and 2-ketoglutarate, which are all candidate compounds for metastable bisulfite complexes (Table 5). Monomeric anthocyanins were evaluated by HPLC and expressed as $\mathrm{mg} / \mathrm{L}$ of malvidin-3-glucoside equivalents. Concentrations of acetaldehyde, pyruvate, and 2-ketoglutarate in the wine samples were determined by HPLC after derivatization reaction with DNPH reagent (Han et al. 2015). We also calculated "metastable bisulfite" as the difference between the A-O and HS-GC methods and performed linear regressions for metastable $\mathrm{SO}_{2}$ binders (monomeric anthocyanins acetaldehyde, pyruvate, and 2-ketoglutarate) against the concentration of metastable bisulfite complexes observed in each wine.

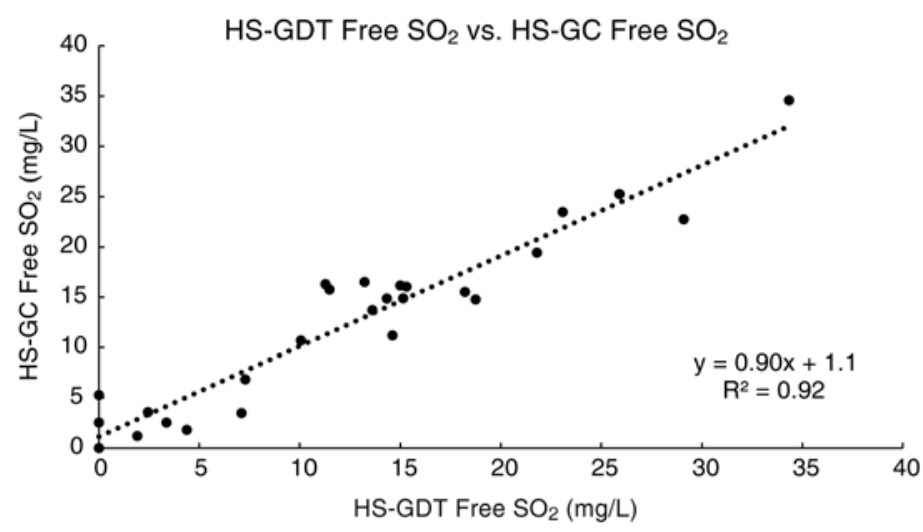

Figure 3 Correlation of free $\mathrm{SO}_{2}$ values measured by the headspace gas detection tube (HS-GDT) and headspace gas chromatography (HSGC) methods.

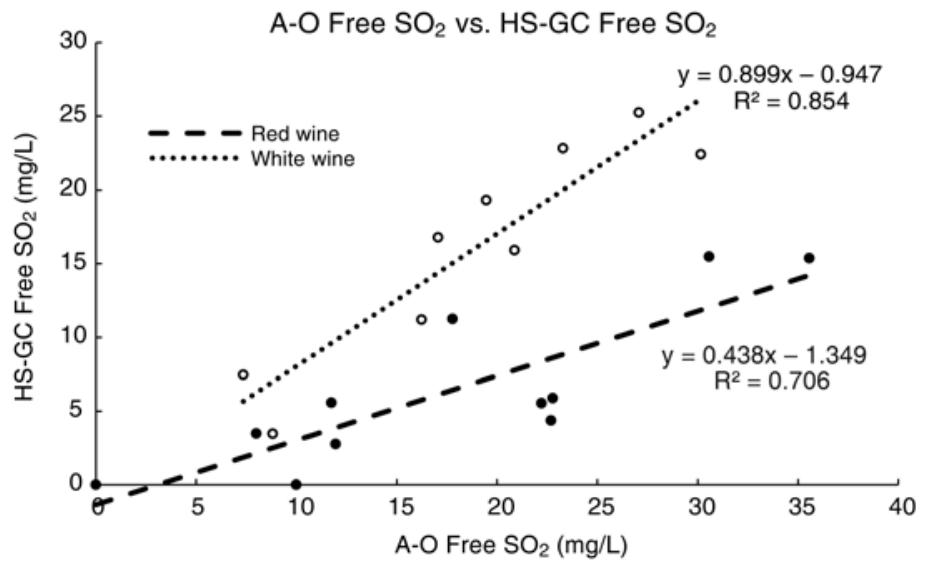

Figure 4 Correlations between aeration-oxidation (A-O) and headspace gas chromatography (HS-GC) methods for red and white wines. 
We observed a significant correlation between monomeric anthocyanins and metastable bisulfite $\left(r^{2}=0.42\right.$, Figure 5). No correlation was observed between metastable bisulfite complexes and acetaldehyde, alpha-ketoglutarate, or pyruvate $\left(\mathrm{r}^{2}<0.1\right.$; plots not shown) in red or white wines, suggesting that these compounds were not related to the discrepancies between methods, similar to findings reported by others (Bisson 1999). Similar correlations were observed to explain the discrepancies in measurements using the Ripper and HS-GDT techniques (data not shown). Anthocyaninbisulfite complexes likely contribute to A-O and Ripper measurements of free $\mathrm{SO}_{2}$ due to their rapid dissociation (first-order rate constant for the dissociation of anthocyaninbisulfite adducts $=0.2 / \mathrm{min}$ ) (Brouillard and Elhagechahine 1980). By comparison, the first-order rate constant glucosebisulfite complex dissociation is $3.7 \times 10^{-4} / \mathrm{min}$ (Vas 1949). Some derived anthocyanin pigments that are known to also bind $\mathrm{SO}_{2}$ or respond to $\mathrm{pH}$ changes (Zimman and Waterhouse 2004) are not quantified by the method presented here. As demonstrated in Coelho et al. (2015), a higher correlation would likely have been found if a different method, such as $\mathrm{SO}_{2}$ bleaching, had been used for total anthocyanin content.
To determine the limit of detection and quantification, model wine solutions containing known trace amounts of molecular $\mathrm{SO}_{2}$ were analyzed with the described HS-GC-SCD method. The signal to noise ratios of each of the $\mathrm{SO}_{2}$ peaks were determined using the ChemStation software (version C.01.07 SR2 [255]). Limit of detection was calculated as the

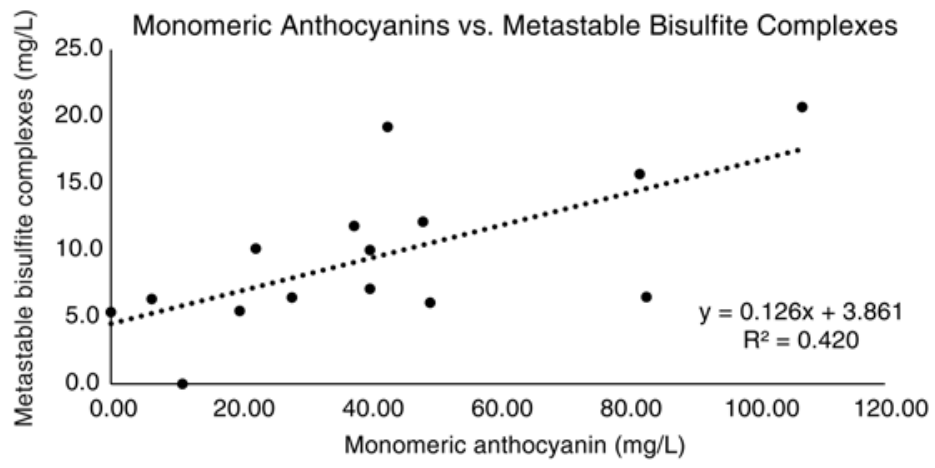

Figure 5 Correlation between metastable bisulfite complexes and anthocyanin concentration (red wines only). Metastable bisulfite complexes were calculated as the difference between free $\mathrm{SO}_{2}$ by aeration-oxidation (A-O) and free $\mathrm{SO}_{2}$ by headspace gas chromatography (HS-GC).

Table 5 Evaluation of metastable bisulfite complexes, total monomeric anthocyanins ( $\mathrm{mg} / \mathrm{L}$ malvidin-3-glucoside equivalents), acetaldehyde, 2-ketoglutarate, and pyruvate on California wines $(n=27)$.

\begin{tabular}{|c|c|c|c|c|c|c|}
\hline Sample ID & Wine type & $\begin{array}{c}\text { Metastable } \\
\text { bisulfite } \\
\text { complexes }^{\mathrm{a}}(\mathrm{mg} / \mathrm{L})\end{array}$ & $\begin{array}{l}\text { Monomeric } \\
\text { anthocyanin } \\
(\mathrm{mg} / \mathrm{L})\end{array}$ & $\begin{array}{l}\text { Acetaldehyde } \\
(\mathrm{mg} / \mathrm{L})\end{array}$ & $\begin{array}{c}\text { 2-Ketoglutarate } \\
\text { (mg/L) }\end{array}$ & $\begin{array}{c}\text { Pyruvate } \\
\text { (mg/L) }\end{array}$ \\
\hline RED & Red & 20.7 & 107.19 & 11.1 & 43.3 & 15.6 \\
\hline ZIN 1 & Red & 19.2 & 42.89 & 22.5 & 67.2 & 12.7 \\
\hline PIN 1 & Red & 15.7 & 81.98 & 3.1 & 35.6 & 10.5 \\
\hline BLAU & Red & 12.1 & 48.40 & 4.6 & 10.1 & 9.9 \\
\hline $\mathrm{CAB}$ & Red & 11.8 & 37.71 & 6.1 & 55.7 & 11.0 \\
\hline ZIN 2 & Red & 10.1 & 22.48 & 9.5 & 67.0 & 8.6 \\
\hline MER 1 & Red & 10.0 & 40.16 & 20.1 & 76.1 & 15.4 \\
\hline SAB 1 & White & 7.4 & 0.00 & 27.5 & 26.6 & 12.3 \\
\hline MER 2 & Red & 7.1 & 40.16 & 12.2 & 28.5 & 17.7 \\
\hline PIN 2 & Red & 6.5 & 83.05 & 10.8 & 39.3 & 11.8 \\
\hline MER 3 & Red & 6.5 & 28.09 & 3.1 & 6.1 & 13.8 \\
\hline ROSE & Rose & 6.4 & 6.32 & 21.2 & 38.9 & 10.5 \\
\hline MOSC 1 & White & 6.3 & 0.00 & 66.0 & 30.2 & 39.6 \\
\hline PIN 3 & Red & 6.1 & 49.52 & 9.8 & 41.4 & 17.7 \\
\hline ZIN 3 & Red & 5.5 & 19.96 & 8.6 & 91.9 & 8.7 \\
\hline $\mathrm{CHA} 1$ & Red & 5.4 & 0.00 & 43.9 & 39.4 & 31.2 \\
\hline $\mathrm{CHA} 2$ & White & 5.0 & 0.00 & 49.5 & 30.9 & 14.1 \\
\hline BRUT & White & 1.8 & 0.00 & 81.9 & 33.6 & 46.8 \\
\hline $\mathrm{CHA} 1$ & White & 1.2 & 0.00 & 54.2 & 37.9 & 15.7 \\
\hline WHITE & White & 0.6 & 0.00 & 39.4 & 22.7 & 14.7 \\
\hline MOSC 2 & White & 0.6 & 0.00 & 24.7 & 42.2 & 13.1 \\
\hline MOSC 3 & White & 0.5 & 0.00 & 47.4 & 0.0 & 18.2 \\
\hline VIO 1 & White & 0.1 & 0.00 & 46.8 & 22.7 & 16.6 \\
\hline PORT & Red & 0.0 & 11.11 & 13.3 & 56.8 & 46.0 \\
\hline SAB 2 & White & $-0.2^{b}$ & 0.00 & 40.1 & 29.5 & 19.1 \\
\hline VIO 2 & White & $-0.5^{b}$ & 0.00 & 27.5 & 26.6 & 13.1 \\
\hline $\mathrm{CHA} 3$ & White & $-1.9^{b}$ & 0.00 & 42.5 & 36.2 & 14.6 \\
\hline
\end{tabular}

aMetastable bisulfite complexes calculated from the difference between free $\mathrm{SO}_{2}$ by aeration-oxidation and free $\mathrm{SO}_{2}$ by headspace gas chromatography.

${ }^{\mathrm{b}}$ Artefact of percent recovery greater than $100 \%$. 
amount of molecular $\mathrm{SO}_{2}$ required to attain a signal to noise ratio of 3 , and the limit of quantification was calculated as the amount of molecular $\mathrm{SO}_{2}$ required to attain a signal to noise ratio of 10 . For the HS-GC-SCD method, the limits of detection and quantification were $0.033 \mathrm{mg} / \mathrm{L}$ and 0.067 $\mathrm{mg} / \mathrm{L}$ molecular $\mathrm{SO}_{2}$, respectively. The similar HS-GC-SCD method published in Ontañón et al. (2019) reported an even lower limit of detection $\left(0.46 \mu \mathrm{g} / \mathrm{L}\right.$ molecular $\left.\mathrm{SO}_{2}\right)$; however, it is not clear how these values were calculated, which makes direct comparison difficult.

The increased significance of headspace versus conventional methods with regard to microbial stability in winemaking has been demonstrated (Howe et al. 2018). Conventional methods detected significant molecular $\mathrm{SO}_{2}$ that should suppress yeast, but no suppression was observed in red wine. By contrast, the headspace method properly predicted suppression at $\sim 0.8 \mathrm{mg} / \mathrm{L}$ molecular $\mathrm{SO}_{2}$.

\section{Conclusion}

Based on a gas detection tube method, we developed an analytical procedure using HS-GC coupled with SCD that can rapidly and precisely quantify molecular and free $\mathrm{SO}_{2}$ in wine. The method requires minimal sample preparation and involves no chemical reagents (with the exception of a trace internal standard). At room temperature $\left(23^{\circ} \mathrm{C}\right)$, the method can successfully detect levels of molecular $\mathrm{SO}_{2}$ at concentrations as low as $0.033 \mathrm{mg} / \mathrm{L}$. The total chromatographic time for the method is eight minutes and, provided that information on the alcohol concentration and $\mathrm{pH}$ is readily available, the molecular and free $\mathrm{SO}_{2}$ concentrations for the sample can be rapidly calculated using simple formulae. The HS-GC method offers a high degree of precision, with a coefficient of variation of $3.72 \%$.

In comparing $\mathrm{SO}_{2}$ analysis methods on a large set of wine samples, the HS-GC method further confirms that conventional $\mathrm{SO}_{2}$ methods systematically overestimate the molecular and free $\mathrm{SO}_{2}$ in red wines, largely due to the presence of anthocyanins. It appears that the presence of anthocyanins in wine leads to formation of metastable complexes with bisulfite that are inadvertently released during conventional analysis methods, leading to inflated and misleading results. Since headspace analysis of $\mathrm{SO}_{2}$ in wine has been shown to predict microbial stability better than conventional methods, the adoption of headspace-based methods may improve prediction of wine stability.

\section{Literature Cited}

Abguéguen O and Boulton RB. 1993. The crystallization kinetics of calcium tartrate from model solutions and wines. Am J Enol Vitic 44:65-75.

Berg HW and Keefer RM. 1958. Analytical determination of tartrate stability in wine. I. Potassium bitartrate. Am J Enol Vitic 9:180-193.

Berg HW and Keefer RM. 1959. Analytical determination of tartrate stability in wine. II. Calcium tartrate. Am J Enol Vitic 10:105-109.

Bisson LF. 1999. Stuck and sluggish fermentations. Am J Enol Vitic 50:107-119.

Boulton RB, Singleton VL, Bisson LF and Kunkee RE. 1996. Principles and Practices of Winemaking, Chapman \& Hall, New York.
Brouillard R and Elhagechahine JM. 1980. Chemistry of anthocyanin pigments. 6. Kinetic and thermodynamic study of hydrogen sulfite addition to cyanin. Formation of a highly stable meisenheimer-type adduct derived from a 2-phenylbenzopyrylium salt. J Am Chem Soc 102:5375-5378.

Buechsenstein JW and Ough CS. 1978. $\mathrm{SO}_{2}$ determination by aerationoxidation: A comparison with ripper. Am J Enol Vitic 29:161-164.

Carrascon V, Ontañón I, Bueno M and Ferreira V. 2017. Gas chromatography-mass spectrometry strategies for the accurate and sensitive speciation of sulfur dioxide in wine. J Chromatogr A 1504:27-34.

Coelho JM, Howe PA and Sacks GL. 2015. A headspace gas detection tube method to measure $\mathrm{SO}_{2}$ in wine without disrupting $\mathrm{SO}_{2}$ equilibria. Am J Enol Vitic 66:257-265.

Collins TS and Boulton RB. 1996. The analysis of free sulfur dioxide and sugars in juices and wines by capillary electrophoresis. In Proceedings of Oenologie 95: 5th Symposium International d'Oenologie. Lonvaud-Funel A (ed.), pp. 637-640. Lavoisier, Paris.

Davis EG, Barnett D and Moy PM. 1983. Determination of molecular and free sulfur-dioxide in foods by headspace gas-chromatography. J Food Technol 18:233-240.

Han GM, Wang H, Webb MR and Waterhouse AL. 2015. A rapid, one step preparation for measuring selected free plus $\mathrm{SO}_{2}$-bound wine carbonyls by HPLC-DAD/MS. Talanta 134:596-602.

Howe PA, Ebeler SE and Sacks GL. 2015. Review of thirteen years of CTS winery laboratory collaborative data. Am J Enol Vitic 66:321-339.

Howe PA, Worobo R and Sacks GL. 2018. Conventional measurements of sulfur dioxide $\left(\mathrm{SO}_{2}\right)$ in red wine overestimate $\mathrm{SO}_{2}$ antimicrobial activity. Am J Enol Vitic 69:210-220.

Iland PG, Ewart A and Sitters J. 1993. Techniques for Chemical Analysis and Stability Tests of Grape Juice and Wine. Patrick Iland Wine Productions, Campbelltown, SA.

Ontañón I, Vela E, Hernández-Orte P and Ferreira V. 2019. Gas chromatographic-sulfur chemiluminescent detector procedures for the simultaneous determination of free forms of volatile sulfur compounds including sulfur dioxide and for the determination of their metal-complexed forms. J Chromatogr A 1596:152-160.

Ough CS, Crowell EA and Benz J. 1982. Metal content of California wines. J Food Sci 47:825-828.

Ripper M. 1892. Die schweflige säure im weine und deren bestimmung. Journal für Praktische Chemie 46:428-473.

Ritchey JG and Waterhouse AL. 1999. A standard red wine: Monomeric phenolic analysis of commercial Cabernet Sauvignon wines. Am J Enol Vitic 50:91-100.

Urbano-Cuadrado M, Luque De Castro MD, Pérez-Juan PM, GarcíaOlmo J and Gómez-Nieto MA. 2004. Near infrared reflectance, spectroscopy and multivariate analysis in enology-Determination or screening of fifteen parameters in different types of wines. Anal Chim Acta 527:81-88.

Usseglio-Tomasset L and Bosia PD. 1984. La prima costante di dissociazione dell'acido solforoso. Vini d'Italia 26:7-14.

Vahl JM and Converse JE. 1980. Ripper procedure for determining sulfur dioxide in wine: Collaborative study. J Assoc Off Anal Chem 63:194-199.

Vas K. 1949. The equilibrium between glucose and sulphurous acid. J Soc Chem Ind-L 68:340-343.

Waterhouse AL, Sacks GL and Jeffery DW. 2016. Understanding Wine Chemistry. John Wiley \& Sons, Ltd, Chichester, West Sussex, UK.

Wells A and Osborne JP. 2011. Production of $\mathrm{SO}_{2}$ binding compounds and $\mathrm{SO}_{2}$ by Saccharomyces during alcoholic fermentaton and the impact on malolactic fermentation. S Afr J Enol Vitic 32:267-279.

Zimman A and Waterhouse AL. 2004. Incorporation of malvidin3-glucoside into high molecular weight polyphenols during fermentation and wine aging. Am J Enol Vitic 55:139-146. 